\title{
ASUHAN KEBIDANAN PADA IBU NIFAS NORMAL KUNJUNGAN II (4-6 HARI) DI BPM DELIANA PEKANBARU TAHUN 2019
}

\author{
Intan Widya Sari ${ }^{1)}$ Reni Anggraini ${ }^{2)}$ \\ STIKes Hang Tuah Pekanbaru \\ Email : intanwidya@htp.ac.id
}

\begin{abstract}
The puerperium is the period after the placenta is born and ends when implans the womb returns to is pre-pregnancy state, the process of restoring helath during the puerperium requires thorough and midwifery care sustainable for mothers after childbirth. Most causes from 50-60\% postpartum hemorrhage due to weakness or absence of contractions uterus most of the maternal morbidity and mortality is caused by failure myometrium contract perfectly, this can be seen from the occurrence of bleeding postpartum in profile riau province health office from year to year no there was a decrease, in 2011 as much as (2,79\%), in 2012 (2,52\%), and in 2013 (2,86\%). This case report aims to find out the benefits care for normal postpartum mothers at least 2 visits includes 1 mothers visit postpartum day 4, visit 2 postpartum mothers on day 6. In this case care is done obstetrics in postpartum mothers with peineal pain during 2 visits to the patient is at the postpartum day 4 to 6 with a visit distance of 1 to the next visit 2 days, the results obtained at the last visit, namely pain in the mothers perineum has decreased because the mother routinely performs care which has been given well, namely perineal care. It is recommended that postpartum visit care used as routine care in every postpartum mother.
\end{abstract}

Keywords $\quad$ : Normal Postpartum, Postpartum Visit, Midwifery Care

\begin{abstract}
ABSTRAK
Masa nifas adalah masa setelah plasenta lahir dan berakhir ketika alat-alat kandungan kembali seperti keadaan sebelum hamil. Proses pemulihan kesehatan pada masa nifas memerlukan asuhan kebidanan yang menyeluruh dan berkesinambungan bagi ibu setelah melahirkan. Penyebab terbanyak dari perdarahan postpartum 50-60\% karena kelemahan atau tidak adanya kontraksi uterus. Sebagian besar kesakitan dan kematian ibu disebabkan oleh kegagalan miometrium berkontraksi secara sempurna, ini terlihat dari kejadian perdarahan postpartum di profil Dinas kesehatan propinsi Riau dari tahun ke tahun tidak terjadi penurunan, pada tahun 2011 sebanyak (2,79\%), tahun 2012 (2,52\%), dan pada tahun 2013 (2,86\%). Laporan kasus ini bertujuan untuk mengetahui manfaat asuhan pada ibu nifas normal minimal 2 kali kunjungan meliputi kunjungan 1 ibu nifas hari ke-4, kunjungan 2 ibu nifas hari ke-6. Dalam kasus ini dilakukan asuhan kebidanan pada ibu nifas dengan nyeri perineum selama 2 kali kunjungan kepada pasien yaitu pada nifas hari ke-4 sampai ke-6 dengan jarak kunjungan 1 ke kunjungan berikutnya 2 hari, hasil yang
\end{abstract}


didapatkan pada kunjungan terakhir yaitu nyeri pada perineum ibu sudah berkurang karena ibu rutin melakukan asuhan yang telah diberikan dengan baik yaitu perawatan perineum. Disarankan agar asuhan kunjungan nifas dijadikan asuhan rutin disetiap ibu post partum.

Kata Kunci : Nifas Normal, Kunjungan Nifas, Asuhan Kebidanan

\section{PENDAHULUAN}

Masa nifas atau masa puerperium adalah masa setelah persalinan selesai sampai 6 minggu atau 42 hari. Selama masa nifas, organ reproduksi secara perlahan akan mengalami perubahan seperti keadaan sebelum hamil. perubahan organ reproduksi ini disebut involusi. Asuhan selama periode nifas perlu mendapat perhatian karena sekitar $60 \%$ angka kematian ibu terjadi pada periode ini (Maritalia, 2014).

Asuhan masa nifas diperlukan dalam periode ini karena merupakan masa kritis baik ibu maupun bayinya. Diperkirakan 60\% kematian ibu akibat kehamilan terjadi setelah persalinan dan $50 \%$ kematian masa nifas terjadi dalam 24 jam pertama (Walyani \& Purwoastuti, 2015b)

$\begin{array}{ccc}\text { Menurut } & \text { World } & \text { Health } \\ \text { Organization(WHO) } & \text { setiap hari di }\end{array}$
seluruh dunia sekitar 830 wanita meninggal akibat komplikasi pada saat kehamilan atau melahirkan. Pada Tahun 2015 AKI mencapai 303.000 selama kehamilan dan persalinan. Sustainable Development Goals(SDGs) memiliki target yaitu Angka Kematian Ibu (AKI) ditargetkan lebih rendah dari 70/100.000 kelahiran hidup serta Angka Kematian Bayi (AKB) lebih rendah dari 12/1000 kelahiran hidup (Kemenkes, 2015)

Tanda-tanda bahaya postpartum (nifas) adalah suatu tanda yang abnormal yang mengindikasikan adanya bahaya atau komplikasi yang dapat terjadi selama masa nifas, apabila tidak dilaporkan atau tidak terdeteksi bisa menyebabkan kematian ibu. Tanda-tanda bahaya postpartum yaitu perdarahan postpartum, infeksi pada masa postpartum, lochea yang berbau busuk (bau dari vagina), sub involusi uterus (pengecilan uterus yang terganggu), nyeri pada perut dan pelvis, pusing dan lemas yang berlebihan, sakit kepala, nyeri epigastrik, penglihatan kabur, suhu tubuh ibu lebih dari 38 derajat celcius, payudara yang merah dan terasa sakit, kehilangan nafsu makan dalam waktu lama, pembengkakan di wajah maupun ekstremitas (Wahyuningsih, 2018)

Perlunya kunjungan nifas karena bidan dapat memberikan asuhan kebidanan selama masa nifas melalui 
kunjungan rumah, untuk membantu ibu dalam proses pemulihan dan memperhatikan kondisi bayi terutama penanganan tali pusat atau rujukan komplikasi yang mungkin terjadi pada masa nifas, serta memberikan penjelasan mengenai masalah kesehatan secara umum, kebersihan, makanan bergizi, perawatan bayi baru lahir, pemberian ASI, imunisasi dan KB. Dengan pemantauan melekat dan asuhan pada ibu dan bayi pada masa nifas dapat mencegah beberapa kematian ibu (Walyani \& Purwoastuti, 2015b)

\section{METODE PENERAPAN}

Metode yang penulis gunakan yaitu dengan cara melakukan asuhan kebidanan sesuai dengan prosedur yang baik dan benar pada pasien Ny "D" umur 27 tahun P1A0, dilaksanakan di PMB Deliana Amd.Keb. Penulis melakukan kunjungan ke rumah pasien, melakukan pendekatan diri dengan cara memperkenalkan diri, dan menanyakan apakah ada keluhan yang dirasakan pasien, setelah mengetahui keluhan pasien yaitu merasakan nyeri di bagian perineum. Dan kemudian penulis melakukan pemeriksaan ttv dan pemeriksaan fisik, dan dari hasil pemeriksaan yaitu ttv dan pemeriksaan fisik dalam batas normal. Penulis memberikan asuhan tentang konseling perawatan luka perineum, konseling makan dan minum, konseling perawatan bayi baru lahir dan konseling cara menyusui yang benar. Asuhan ini dilakukan sebanyak 2 kali kunjungan untuk melihat apakah perubahan pada ibu termasuk fisiologis normal.

\section{HASIL DAN PEMBAHASAN}

\section{A. HASIL}

\section{Kunjungan ke-I}

Kajian pertama dilakukan pada Ny. D post partum 4 hari tanggal 27 Agustus 2020 pukul 14:00 WIB di rumah pasien.

\section{Data Subjektif}

Ibu mengatakan merasa nyeri dibagian perineum. Ibu sudah bisa duduk, berdiri, dan berjalan dengan perlahan.

\section{Data Objektif}

TTV ibu dalam batas normal, TFU pertengahan symphisis pusat, robekan jalan lahir derajat 2, lochea sanguinolenta yang berwarna merah kekuningan berisi darah dan lendir.

\section{Assesment}

P1A0 Post Partum 4 hari dengan perubahan fisiologis normal.

\section{plan}

Informasi dan Edukasi :

1. Hubungan baik dengan ibu. 
2. Pemeriksaan ttv dan pemeriksaan fisik head to toe.

3. Memberitahu ibu tentang perawatan perineum

4. Pemberian konseling perawatan bayi baru lahir.

5. Pemberian konseling tentang makanan dan minuman.

6. Menjelaskan tentang ASI ekslusif dan manfaatnya.

7. Evaluasi pemahaman ibu.

8. Kunjungan ulang.

\section{Lembar implementasi}

Informasi dan Edukasi :

1. Menjalin hubungan baik dengan ibu dan keluarga dengan penuh ramah dan sopan.

2. Menginformasikan hasil pemeriksaan kepada ibu dan keluarga bahwa keadaan umum ibu baik dan normal.
a. TD : $110 / 70 \mathrm{mmHg}$
b. $\mathrm{N}: 82 \mathrm{x} / \mathrm{menit}$
c. $\mathrm{P}: 21 \mathrm{x} / \mathrm{menit}$
d. $\mathrm{S}: 36,6^{\circ} \mathrm{C}$
e. TFU : pertengahan symphisis pusat

f. Lochea : sanguinolenta

g. Pemeriksaan fisik normal

3. Memberi tahu tentang perawatan luka perineum

a. Menjaga kebersihan area perineum,tetap disarankan mandi dua kali sehari untuk menjaga kebersihan badan dan area perineum. Dan setiap selesai mandi luka jahitan di kompres dengan kassa yang diberi betadine.

b. Ganti pembalut 2-4 jam sekali selama perdarahan nifas berlangsung.

c. Minum obat pereda nyeri, seperti paracetamol, atau ibuprofen.

4. Pemberian konseling tentang perawatan bayi baru lahir.

a. Memandikan bayi

Memandikan bayi menggunakan air hangat, dan jangan terlalu lama bayi di dalam air agar tidak terjadi hipotermi, pakaikan baju dan topi agar menjaga kehangatannya.

b. Perawatan tali pusat

Pastikan dalam keadaan kering, bungkus dengan kassa steril yang diberi betadine, biasanya akan lepas sebelum 1-2 minggu.

c. Menjaga kebersihan kemaluan Bersihkan dengan air selesai BAB/BAK dan hindari menggunakan popok diapers sepanjang hari.

d. Menjaga kehangatan bayi

Selalu menjaga kehatan bayi dengan menggunakan bedong, sarung tangan, sarung kaki, dan juga topi.

e. Perawatan kuku bayi 
Gunting kuku bayi setiap panjang pada saat dia tidur dengan hatihati.

f. Perawatan mata bayi Bersihkan mata bayi dengan kapas bulat yang di celupkan air hangat.

g. Perawatan telinga bayi Bersihkan dengan menggunakan cotton but yang ujungnya dibasahi air hangat.

h. Menidurkan bayi

i. Bayi tidur lebig kurang 16 jam/hari, pasang kelambu saat bayi tidur siang/malam dan pastikan bayi aman.

5. Memberikan konseling tentang makanan dan minuman.

a. Minum air putih sekitar 2 liter perhari agar terhindar dari dehidrasi yang dapat mengganggu masa pemulihan dan masa menyusui.

b. Minum susu rendah lemak untuk menjaga kebugaran dan kesehatan ibu pasca melahirkan

c. Makan sayuran hijau seperti bayam, brokoli, kangkung, buncis, dan sayuran lainnya karena sayuran hijau juga merupakan salah satu sumber kalsium.

d. Karbohidrat tinggi serat, bias didapat dari beras merah, dan gandum. Selain kandungannya yang sangat bermanfaat, karbohidrat tinggi serat juga sangat baik dalam mendukung program diet ibu.

e. Asupan protein dapat diperoleh dari telur, daging, ikan, dan kedelai.

f. Buah kaya vitamin C seperti anggur dan jeruk.

6. Menjelaskan tentang ASI esklusif dan manfaatnya

ASI eksklusif diberikan sejak bayi lahir hingga berusia enam bulan. Selama periode tersebut, disarankan hanya memberi ASI kepada bayi, tanpa tambahan asupan apa pun. Sebab, ada banyak manfaat ASI eksklusif yang bisa didapatkan oleh bayi. Manfaatnya yaitu

a. Sistem kekebalan tubuh bayi lebih kuat.

b. Membuat bayi menjadi cerdas.

c. Berat badan bayi menjadi ideal.

d. Tulang bayi menjadi lebih kuat.

e. Memperkuat hubungan ibu dan bayi.

7. Mengevaluasi kembali tentang pemahaman ibu.

Ibu sudah mengerti dan sudah bisa melakukan perawatan perineum dan perawatan bayi baru lahir. 
8. Memberitahu ibu bahwa penulis akan melakukan kunjungan kembali 2 hari lagi.

\section{Kunjungan ke-II}

Kajian kedua dilakukan pada Ny. D post partum 6 hari tanggal 29 Agustus 2020 pukul 10:00 WIB di rumah pasien.

\section{Data Subjektif}

Ibu mengatakan tidak ada keluhan yang sedang dirasakan, nyeri pada luka perineum sudah berkurang.

\section{Data Objektif}

TTV ibu dalam batas normal, TFU pertengahan symphisis pusat, robekan jalan lahir derajat 2, lochea sanguinolenta yang berwarna merah kekuningan berisi darah dan lendir.

\section{Assesment}

P1A0 Post Partum 6 hari dengan k/u ibu baik

\section{Plan}

1. Pemeriksaan fisik head toe to dan ttv.

2. Kembali tentang nyeri perineum yang dirasakan ibu.

3. Pemberian konseling tentang teknik menyusui yang benar.

4. Teknik melepaskan hisapan bayi.

5. Memberitahu ibu tanda bahaya nifas.

6. Evaluasi pemahaman ibu.

\section{Lembar Implementasi}

1. Menginformasikan hasil pemeriksaan kepada ibu dan keluarga bahwa keadaan umum ibu baik dan normal.
a. TD : 100/60 $\mathrm{mmHg}$
b. $\mathrm{N}: 82 \mathrm{x} / \mathrm{menit}$
c. $\mathrm{P}: 21 \mathrm{x} / \mathrm{menit}$
d. $\mathrm{S}: 36,6{ }^{\circ} \mathrm{C}$
e. TFU : pertengahan symphisis pusat
f. Lochea : sanguinolenta
g. Pemeriksaan fisik normal

2. Menanyakan kembali tentang nyeri perineum yang dirasakan ibu.

Ibu mengatakan nyeri perineum yang dirasakan sudah berkurang.

3. Mengajarkan teknik menyusui yang benar

a. Cuci tangan dengan sabun, posisi duduk/berbaring dengan santai.

b. Bila dimulai dengan payudara kiri, letakkan kepala bayi pada siku bagian dalam lengan kiri.

c. Lengan kiri bayi diletakkan diseputar pinggang ibu, tangan kiri ibu memegang pantat/paha kanan bayi.

d. Sangga payudara kiri ibu dengan empat jari tangan kanan, ibu jari di atasnya.

e. Sentuhlah mulu bayi dengan putting payudara ibu. 
f. Tunggu sampai bayi membuka mulut nya.

g. Masukkan putting payudara secepatnya ke dalam mulut bayi sampai bagian areola.

4. Mengajarkan teknik melepaskan hisapan bayi

a. Masukkan jari kelingking ibu yang bersih kesudut mulut bayi.

b. Menekan dagu bayi ke bawah dengan menutup lubang hidung bayi agar mulutnya membuka.

c. Jangan menarik putting susu untuk melepaskan.

5. Memberitahu ibu tanda bahaya nifas

a. Sakit kepala, penglihatan kabur, pembengkakan wajah.

b. Gangguan buang air kecil.

c. Sesak napas dan nyeri dada

d. Nyeri dan bengkak di betis.

e. Demam tinggi (lebih dari $38^{\circ} \mathrm{C}$ ).

6. Mengevaluasi kembali tentang pemahaman ibu

Ibu sudah mengerti dan sudah bisa melakukan teknik menyusui yang benar dan cara melepaskan hisapan bayi.

\section{B. PEMBAHASAN}

1. Data Subjektif

Data subjektif yang ditemukan pada Ibu nifas 4 hari yaitu ibu merasa nyeri dibagian perineum. Menurut teori Maritalia,(2014) mengatakan bahwa pada ibu nifas sering mengalami nyeri pada perineum yang disebabkan karena adanya robekkan pada jalan lahir. Keadaan ini merupakan tingkatan rasa sakit yang timbul akibat hecting perineum pada ibu postpartum.

Menurut teori Dewi dan Sunarsih, (2011) luka perineum dapat kembali sembuh dalam kurun waktu lebih kurang 2 minggu pasca persalinan.

Untuk mengatasi keluhan nyeri perineum pada ibu penulis memberi tahu tentang perawatan luka perineum yaitu menjaga kebersihan area perineum, disarankan mandi dua kali sehari untuk menjaga kebersihan badan dan area perineum. setiap selesai mandi luka jahitan di kompres dengan kassa yang diberi betadine, ganti pembalut 2-4 jam sekali selama perdarahan nifas berlangsung dan minum obat pereda nyeri, seperti paracetamol, atau ibuprofen.

Pada pengkajian kunjungan ke 2 dari data subjektif ibu mengatakan bahwa nyeri perineum yang dirasakan sudah berkurang dan luka jahitan sudah mulai kering.

2. Data Objektif

Data objektif yang ditemukan pada kunjungan pertama sampai terakhir yaitu keadaan umum ibu baik, tekanan darah 110/70 $\mathrm{mmHg}$, denyut 
nadi $82 \mathrm{x} / \mathrm{i}$, pernafasan $21 \mathrm{x} / \mathrm{i}$, suhu $36,6{ }^{\circ} \mathrm{C}$, kelopak mata ibu tidak pucat, konjungtiva merah muda, sklera putih, pada mammae colostrum/ASI (+) banyak, puting susu menonjol, ibu tidak ada merasakan benjolan maupun rasa nyeri, kebersihan baik, hasil pemeriksaan TFU pertengahan symphisis pusat, kontraksi baik, sesuai dengan teori Indriyani,(2013) proses involusi uterus disertai dengan penurunan tinggi fundus uteri pada saat bayi baru lahir yaitu setinggi pusat, pada 2-3 hari postpartum tinggi fundus uteri 3 jari dibawah pusat, pada postpartum 1 minggu tinggi fundus uteri pertengahan symphisis pusat, pada 2 minggu dan 6 minggu sudah tidak teraba lagi. Dari pemeriksaan lochea terdapat berwarna merah kekuningan dan berlendir (sanguinolenta) sesuai dengan teori Sunarsih, (2011) yang menyatakan Lochea ini berwarna merah kuning berisi darah dan lendir karena pengaruh plasma darah, pengeluarannya pada hari ke 3-5 hari postpartum.

\section{Assesment}

Assessment yang dapat ditegakkan pada asuhan kebidanan ini adalah P1A0 postpartum 4-6 hari dengan perubahan fisiologis normal. Karena dari pemeriksaan ttv dalam batas normal, perubahan TFU normal pertengahan symphisis pusat, lochea yang keluar normal yaitu sanguinolenta, dan itu termasuk dalam perubahan fiologis normal.

4. Plan

Menurut (Metha, 2019) Plan mengambarkan pendokumentasi tindakan dan evaluasi perencanaan, implementasi berdasarkan pengumpulan data subjektif, objektif, dan assasment sesuai kebutuhan pasien. Plan pada kasus ini penulis memberikan pendidikan kesehatan tentang:

Pemeriksaan ttv $_{\text {pemeriksaan tanda }}$ tanda vital
pem
merupakan cara yang cepat dan efisien untuk memantau kondisi klien atau mengidentifikasi masalah dan mengevaluasi respon klien terhadap intervensi. Tanda-tanda vital atau tanda-tanda dasar meliputi: Pemeriksaan Suhu Tubuh, Pemeriksaan Denyut Nadi, Pemeriksaan Pernafasan, Pemeriksaan Tekanan Darah. Menurut (Marmi, 2014) pemeriksaan ttv perlu dilakukan pada ibu nifas yang bertujuan untuk mengetahui keadaan umum apakah dalam batas normal.

Pemeriksaan head to toe merupakan salah satu cara mengetahui gejala atau masalah kesehatan yang 
dialami oleh ibu nifas dengan mengumpulkan data objektif dilakukan pemeriksaan terhadap pasien. Pemeriksaan fisik ibu post partum sangat penting dilakukan untuk dapat mendeteksi keadaan ibu apakah normal ataukah terdapat abnormalitas yang disebabkan oleh proses persalinan. Asuhan kebidanan merupakan suatu penerapan fungsi dan kegiatan yang menjadi tanggung jawab dalam memberikan pelayanan kebidanan pada pasien yang mempunyai kebutuhan atau masalah dalam bidang kesehatan, ibu pada masa hamil, nifas, dan bayi baru lahir serta keluarga berencana (Wahyuningsih, 2018)

Pemberian konseling tentang perawatan perineum adalah upaya memberikan pemenuhan kebutuhan rasa nyaman dengan caa menyehatkan daerah antara kedua paha yang dibatasi antara lubang dubur dan bagian alat kelamin luar pada wanita yang habis melahirkan agar terhindar dari infeksi (Kumalasari, 2015).

Pemberian konseling tentang perawatan bayi baru lahir adalah masa bayi baru lahir (neonatal) adalah masa 28 hari pertama kehidupan manusia. Pada masa ini terjadi proses penyesuaian sistem tubuh bayi dari kehidupan dalam rahim ke kehidupan di luar rahim. Masa ini adalah masa yang perlu mendapatkan perhatian dan perawatan yang ekstra karena pada masa ini terdapat mortalitas paling tinggi (Maritalia, 2014).

Pemberian konseling tentang makanan dan minuman yaitu 1 sampai 2 piring, daging, ikan, ayam, sayursayuran, buah buahan dan air putih setiap harinya minimal $8-10$ gelas dan minum setiap kali mau menyusui agar ibu nifas tidak mengalami dehidrasi (Marmi, 2014).

Pemberian konseling tentang teknik menyusui yang benar adalah teknik menyusui dengan cara memberikan ASI kepada bayi dengan perlekatan dan posisi ibu dan bayi dengan benar dan ini sangat penting diajarkan kepada ibu terutama pada ibu yang pertama kali mempunyai bayi (Maritalia, 2014)

\section{KESIMPULAN}

Asuhan kebidanan pada ibu nifas normal kunjungan II (4-28 hari) di PMB Deliana Amd.Keb Pekanbaru dilaksanakan menggunakan pendekatan dengan pendokumentasi SOAP (subjektif, objektif, assessment, dan plan). Setelah mengumpulkan data secara keseluruhan dapat dibuat kesimpulan yaitu: 
Setelah penulis mendapatkan persetujuan pasien bahwa akan dilakukan pemeriksaan, penulis dapat mengumpulkan data subjektif dan data objektif saat melakukan pengumpulkan data penulis tidak menemukan kesulitan karena pasien bersedia kerja sama. Penulis tidak menemukan kesenjangan pada hasil data subjektif dan data objektif. Setelah semua data terkumpul penulis dapat menyimpulkan analisa sesuai dengan data yang telah dikumpulkan. Assasment yaitu P1A0 Post partum 46 hari dengan perubahan fisiologis normal.

\section{DAFTAR PUSTAKA}

Asih, Y., \& Risneni. (2016). Buku Ajar Asuhan Kebidanan Nifas Dan Menyusui (ke-1). CV.Trans Info Media.

Dewi, vivian N. L., \& Sunarsih, T. (2011). Asuhan Kebidanan Pada Ibu Nifas. Salemba Medika.

Indriyani, D. (2013). Aplikasi Konsep \& Teori Keperawatan Maternitas Post Partum Dengan Kematian Janin (Ke-1). AR-RUZZ MEDIA.

Kemenkes, R. (2015). Profil Kesehatan RI 2015. In Profil Kesehatan
Indonesia

Tahun

2015.

https://doi.org/10.1111/evo.12990

Maritalia, D. (2014). Asuhan Kebidanan Nifas Dan Menyusui (ke-2). PUSTAKA PELAJAR.

Marmi. (2014). Asuhan Kebidanan Pada Masa Nifas Puerperium Care (Ke2). PUSTAKA PELAJAR.

Nugroho, T., Nurrezki, Warnaliza, D., \& Wilis. (2014). Buku Ajar Asuhan Kebidanan 3 Nifas (ke-1). Nuha Medika.

Reinissa, A., \& Indrawati, F. (2017). Persepsi Ibu Nifas tentang Pelayanan Postnatal Care dengan Kunjungan Ulang. Higeia Journal of Public Health.

Rukiyah, A. Y., \& Yulianti, L. (2011). Asuhan Kebidanan IV (Patologi Kebidanan). CV. Trans Info Media.

Rukiyah, A. Y., \& Yulianti, L. (2014). Asuhan Kebidanan Kehamilan Berdasarkan Kurikulum Berbasis Kompetensi (Pertama). CV. Trans Info Media.

Sari, D. P. (2019). Persepsi Ibu Nifas terhadap Pelayanan Kunjungan Nifas Mother's Perception of the Post Partum Visit Services. BIOMEDIKA, 12(01). 
Sukarni, I., \& Margareth. (2013). Kehamilan, Persalinan, Dam Nifas (Ke-1). Nuha Medika.

Wahyuningsih, H. P. (2018). Bahan Ajar Kebidanan: Asuhan Kebidanan Nifas dan Menyusui. In Kemenkes $R I$.

Walyani, E. S., \& Purwoastuti, E. (2015a). Asuhan Kebidanan Kegawatdaruratan Maternal \& Neonatal (ke-1). PUSTAKABARUPRESS.

Walyani, E. S., \& Purwoastuti, T. E. (2015b). Asuhan Kebidanan Masa Nifas \& Menyusui (ke-1). PUSTAKABARUPRESS. 
